\title{
Pasteurella haemolytica var. ureae from human sputum
}

\author{
D. M. JONES AND P. M. O'CONNOR \\ From the Public Health Laboratory and the Chest Clinic, Manchester
}

SYNOPSIS A new variety of Pasteurella, named by Henriksen and Jyssum (1960, 1961) Past. haemolytica var. ureae, has been isolated from the sputum of 17 patients, most of them elderly, suffering from chronic bronchitis or bronchiectasis. It has also been found in the normal respiratory tract. Whether the organism aggravates the disease or acts as a mere commensal when growing in the damaged tissue is not yet clear.

Recently Henriksen and Jyssum (1960, 1961) described the isolation from the human upper respiratory tract of a Pasteurella-like organism not previously recorded in the literature. They have named this organism 'Pasteurella haemolytica var. ureae'. They isolated it from three patients with rhinosinusitis and from one with ozaena. In three of these instances other organisms of recognized pathogenicity were also present. Two further isolations of this organism have also been reported by Omland and Henriksen (1961).

One of us (D.M.J.) has isolated a number of strains of Pasteurella haemolytica var. ureae from routine sputum specimens. A detailed account of their bacteriology appears elsewhere (Jones, 1962). When a newly described organism is isolated it is of interest to determine what part it plays in the disease process of the patients. We wish to record here the type of case in which we have found this organism. In view of the well-known difficulty in assessing the role of any organism in the pathology of chronic bronchitis or bronchiectasis we are aware of the hazards of drawing any conclusions from such a small series as this.

\section{FREQUENCY}

The organism has been isolated from about $1 \%$ of routine sputum specimens examined, and we have found it to occur four or five times more frequently than Pasteurella septica in the same material.

\section{BACTERIOLOGY}

We have examined nearly 30 strains of $P$. haemolytica

Received for publication 24 November 1961. var. ureae and they appear to form a homogeneous group, resembling each other closely. They are nonsporing, non-motile, Gram-negative rods, differing from $P$. septica in being larger, 0.5 to $0.7 \mu$ wide, and variable in length with a tendency to form short filaments. Most of the strains we have seen have been capsulated. The colonies on blood agar are mucoid and somewhat similar in size and appearance to those of $P$. septica. There is no true haemolysis of horse blood agar but some greening of the medium occurs after 48 hours' incubation. Glucose, maltose, fructose, sucrose, and mannitol are fermented promptly and produce acid only. No indole is produced. All strains are very strongly urease positive on Christensen's urea agar (Christensen, 1946). The oxidase test (Kovacs, 1956) is positive; only small amounts of catalase are formed. There is no growth on MacConkey agar. Like $P$. septica, this organism is sensitive to penicillin, tetracycline, streptomycin, erythromycin, and chloramphenicol. No strain we have examined has been pathogenic for small laboratory animals.

\section{CASE HISTORIES}

These are summarized in the Table on page 248 .

\section{DISCUSSION}

In nearly all our cases the colonies of Pasteurella haemolytica var. ureae predominated or were present in large numbers on the primary blood agar plates. It would seem that in these cases this organism formed an integral part of the respiratory tract flora. We have isolated it from the respiratory tract in the absence of symptoms from cases of acute bronchitis 
TA B LE

SUMMARY OF CASES EXAMINED ${ }^{1}$

\begin{tabular}{|c|c|c|c|}
\hline Case No. & Age & $\operatorname{Sex}$ & Case History \\
\hline 1 & 55 & $\mathbf{M}$ & $\begin{array}{l}\text { Inactive pulmonary tuberculosis, bronchiectasis, } \\
\text { and chronic bronchitis }\end{array}$ \\
\hline 2 & 70 & $\mathbf{M}$ & Mild chronic bronchitis \\
\hline 3 & 58 & $\mathbf{M}$ & $\begin{array}{l}\text { No history of chronic respiratory disease. } \\
\text { Admitted with small left pleural effusion which } \\
\text { cleared rapidly }\end{array}$ \\
\hline 4 & 61 & $\mathbf{M}$ & Chronic bronchitis for 6 years, recent deterioration \\
\hline 5 & 58 & $\mathbf{M}$ & $\begin{array}{l}\text { Discharging sinus after oesophagectomy; } \\
\text { no respiratory symptoms }\end{array}$ \\
\hline 6 & 21 & $\mathbf{F}$ & Bronchiectasis \\
\hline 7 & 38 & $\mathbf{M}$ & Chronic bronchitis since childhood \\
\hline 8 & 44 & $\mathbf{F}$ & Bronchitis since childhood \\
\hline 9 & 44 & $\mathbf{M}$ & $\begin{array}{l}\text { Chronic bronchitis. Admitted on several occasions } \\
\text { with acute exacerbations }\end{array}$ \\
\hline 10 & 3 & $\mathbf{F}$ & Dysentery, no respiratory symptoms \\
\hline 11 & 72 & $\mathbf{M}$ & Carcinoma bronchus \\
\hline 12 & 63 & $\mathbf{M}$ & Inactive tuberculosis and chronic bronchit is \\
\hline 13 & 15 & $\mathbf{M}$ & Bilateral bronchiectasis \\
\hline 14 & 16 & $\mathbf{F}$ & Bronchiectasis \\
\hline 15 & 30 & $\mathbf{M}$ & $\begin{array}{l}\text { Acute bronchitis following common cold. No } \\
\text { chronic chest disease. Pasteurellae not isolated } \\
\text { from nose swabs in absence of symptoms }\end{array}$ \\
\hline 16 & 60 & $\mathbf{F}$ & Chronic bronchitis \\
\hline 17 & 51 & $\mathbf{M}$ & Chronic bronchitis \\
\hline
\end{tabular}

Comments

Acute exacerbation

Admitted with dysentery

No clear cause established

Heavy growth of both pasteurellae and pneumococci Pasteurellae grown from sputum on two admissions at an interval of 6 months

Pasteurellae and pneumococci isolated Acute exacerbation

Pasteurellae together with pneumococci isolated during one admission

Pasteurellae from nasal swab

Pasteurellae and Friedländer's bacillus

Acute exacerbation

Pasteurellae isolated three times during one month

Pasteurellae during two exacerbations at an interval of one year

Pasteurellae isolated again eight months later during another acute episode

Unresolved pneumonia

Acute exacerbation

${ }^{1}$ A strain of $\boldsymbol{P}$. haemolytica var. ureae was isolated as the predominant growth in a case of post-operative pneumonia. This patient died three days after operation and at necropsy a bilateral bronchopneumonia was present but cultures taken were overgrown with coliforms.

and from cases with exacerbations of chronic chest disease. Pasteurella septica has been encountered in association with chronic chest disease (Mulder, 1938; Bezjak and Mimica, 1952; Cawson and Talbot, 1955). The organism we describe here, although easily distinguished from $P$. septica, is almost certainly closely related to it. Though both $P$. septica and $P$. haemolytica var. haemolytica are recognized animal pathogens there is no record of an organism resembling $P$. haemolytica var. ureae occurring in animals and it may prove to be restricted to the human host.

Possibly $\boldsymbol{P}$. haemolytica var. ureae behaves in the same way as Haemophilus influenzae; that is to say, it may be present in the upper respiratory tract as part of the normal commensal flora and may invade a damaged bronchial tree when conditions are $\overrightarrow{\vec{P}}$ favourable.

We wish to thank the chest physicians at Monsallo Hospital, Manchester, under whose care most of these patients were admitted.

\section{REFERENCES}

Bezjak, V., and Mimica, M. (1952). Brit. med. J., 2, 757.

Cawson, R. A., and Talbot, J. M. (1955). J. clin. Path., 8, 49.

Christensen, W. B. (1946). J. Bact., 52, 461.

Henriksen, S. D., and Jyssum, K. (1960). Acta path. microbiol. scand. D $50,443$.

- - (1961). Ibid., 51, 354.

Jones, D. M. (1962). J. Path. Bact. 83, 143.

Kovacs, N. (1956). Nature (Lond.), $178,703$.

Mulder, J. (1938). Acta med. scand., 97, 165.

Omland, T., and Henriksen, S. D. (1961). Acta path. microbiol. scand., N $53,117$. 